\title{
COMMENTARY ON COVID-19 AND THE FoOd SYSTEM
}

\section{Nimble in a pandemic: Lessons learned from Concrete Jungle's Grocery Delivery Program}

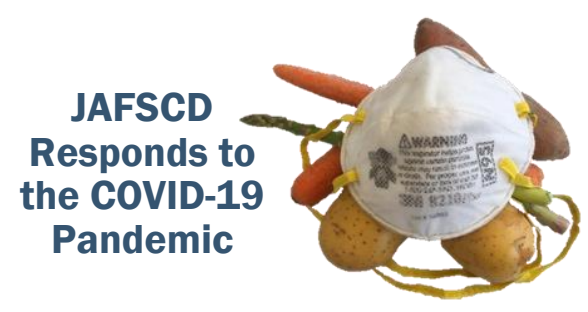

\author{
Rachel Blacher ${ }^{a *}$ and Nichole Fields-Kyle ${ }^{b}$ \\ Concrete Jungle
}

Submitted October 20, 2020 / Published online February 7, 2021

Citation: Blacher, R., \& Fields-Kyle, N. (2021). Nimble in a pandemic: Lessons learned from

Concrete Jungle's Grocery Delivery Program. Journal of Agriculture, Food Systems, and Community

Development, 10(2), 265-268. https://doi.org/10.5304/jafscd.2021.102.011

Copyright (C 2021 by the Authors. Published by the Lyson Center for Civic Agriculture and Food Systems. Open access under CC-BY license.

A s a leader in Atlanta's fresh produce supply chain for people with limited access to fruits and social service community organizations to support Atlanta's food-insecure population. Founded in 2009, CJ is an Atlanta-based nonprofit organization that coordinates approximately 1,700 volunteers annually to pick produce within the city and across Georgia and delivers it to community food distribution partners. CJ staff and volunteers also lead healthy food recipe demonstrations. To date, CJ has picked 158,292 pounds (633,169 servings) of produce within Atlanta and across Georgia.

The relationship between food insecurity, low produce consumption, and increased prevalence of chronic diseases is well documented. Evidence shows that food-insecure individuals are more likely to have high blood pressure and type 2 diabetes (Gucciardi, Vahabi, Norris, Del Monte, \& Farnum, 2014; Weinfield et al., 2014). And, while increased fruit and vegetable consumption can lower the risk of developing these and other chronic conditions, food-insecure people are less likely to have access to fresh produce (Boeing et al., 2012; Hung et al., 2004; Volpe, 2019).

a* Corresponding author: Rachel Blacher, MPH, Member, Advisory Board, Concrete Jungle; 5209 Foothills Trail, NE; Albuquerque, NM 87111 USA; riblacher@gmail.com

b Nichole Fields-Kyle, MPH, Program Manager, Concrete Jungle; nichole@,concrete-jungle.org

\section{Acknowledgments}

The authors wish to acknowledge the staff and volunteers at Concrete Jungle who have worked tirelessly to ensure that food supplies are not disrupted for Atlantans impacted by food insecurity and COVID-19. 
In this commentary, we describe how Concrete Jungle leveraged its food collection and distribution model, along with its partners and volunteer base, to ensure that food-insecure people did not go hungry during the initial months of the COVID-19 pandemic. We also consider some of the challenges in sustaining this model.

\section{Response to COVID-19: Timeline and Need}

In March, CJ staff realized that the community spread of COVID-19 would drastically limit the organization's ability to operate normal programming. The staff recognized the urgent need to maintain the fresh produce supply chain while mitigating the risks of COVID-19 for client and staff health. In addition, the city of Atlanta's emergency policies precluded community food pantries from maintaining normal operations. City officials specifically informed one of CJ's food partners, the Southwest Ecumenical Emergency Assistance Center (SWEEAC), that the organization could no longer operate because of potential client COVID-19 infection.

On March 23, 2020, CJ staff met food pantry clients outside SWEEAC to assess their interest and the feasibility of pantry grocery home delivery. The response was overwhelmingly positive, and 20 clients signed up immediately. News spread that CJ was offering this service, and soon seniors and families were calling CJ to be added to the list for grocery delivery. United Way soon began using its 2-1-1 line to advertise the nascent food delivery program.

By the end of March, CJ launched the COVID-19 Grocery Delivery Program (GDP) to serve foodinsecure Atlantans who self-identify as being at high risk of COVID-19. CJ provided no-contact deliveries for 90 families in the program's first week, 180 families in the second week, and over 400 households in June. As of July 31, 2020, 300 families were receiving weekly deliveries.

\section{The Grocery Delivery Program}

The GDP uses three no-contact methods to deliver groceries: food pantry suppliers, grocery depots, and family sponsorships. Having these different methods allows CJ to maximize the program's impact by using different resources and partnerships.

\section{Food Pantry Suppliers}

Food pantry partners create one week's worth of groceries, including produce and shelf-stable food for clients. CJ supplements the grocery boxes with recovered produce. Volunteer drivers pick up the boxes from pantries and make a no-contact delivery to clients on a specified list.

\section{Grocery Depots}

CJ purchases and aggregates donated groceries at two "depots" located near clusters of clients. Depots are sites that are shared with other social service organizations that have refrigerator space to share with CJ. Volunteer drivers pick up from the depots and make no-contact deliveries. Perishable items, such as meat and dairy, are available biweekly.

\section{Family Sponsorships}

In family sponsorships, CJ matches volunteers to food-insecure households. Volunteers purchase weekly groceries for a specific household and make no-contact delivery. Seasonal produce comes from partner organizations and Georgia farmers. CJ provides volunteers with suggested shopping lists.

\section{Volunteers}

CJ has always relied on an army of committed volunteers, who are the organization's greatest asset. To launch the GDP, CJ tapped its volunteer database to recruit packers, delivery drivers, and client callers. 
The GDP engages approximately 150 volunteers weekly for shopping, packing, and delivery, as well as managing communications and logistics.

\section{Partnerships}

Throughout COVID-19, partnerships have played an important role in supplementing produce delivery and providing social support for clients who need more support than just food, such as mental health or housing assistance. Without these partnerships, CJ would not be able to advance its mission.

\section{Challenges and Next Steps}

Despite GDP's initial successes — a rapid scale up of a multifaceted model to engage all levels of volunteers, as well as critical partnerships_-four key challenges exist.

1. As people adapt to their "new normal," volunteer fatigue is setting in. While sponsors have shown great generosity through client sponsorships for months, many have discontinued their support. CJ is spending more time recruiting volunteers.

2. Clients' needs go beyond food donations, including housing support and mental health services. CJ has resource lists for clients, but clients frequently need additional support.

3. Emergency funding opportunities and the partnership landscape have changed since the initial period, threatening overall sustainability as CJ takes on more direct expenses.

4. Finally, CJ is a small organization, with two full-time employees and several part-time staff. GDP operation requires a majority of staff time, plus commitment from many volunteers. While GDP is needed in the community, CJ's staff need to ensure that its other programs do not suffer.

One way that $\mathrm{CJ}$ is addressing these challenges is by conducting a community assessment to better understand client perspectives about the program, and by potentially shifting to a nutrition education program.

CJ is operating in an environment devoid of coordination on a larger scale. If a larger and betterresourced entity, such as the Atlanta Community Food Bank or the city of Atlanta, coordinated a plan with local food donation organizations, CJ could better meet the needs of the community. By outlining each organization's approach and the communities they serve, we can identify overlapping services, find program inefficiencies, and discover gaps in service that, when addressed, could have a positive effect for food-insecure Atlantans.

\section{Conclusion}

Early in the pandemic, CJ rapidly pivoted its food distribution model and developed a program to safely serve food-insecure households. As COVID-19 continues into 2021, CJ must critically assess how best to serve our community while meeting our organizational mission and remain a viable organization. CJ's experience during the COVID-19 pandemic demonstrates that small, grassroots volunteer networks can serve hundreds of food-insecure households safely during an emergency; however, these households deserve fresh produce and healthy staples at all times. Lessons learned from CJ's GDP can inform future programming for food-insecure populations in a post-COVID world.

\section{References}

Boeing, H., Bechtold, A., Bub, A., Ellinger, S., Haller, D., Kroke, A., . . \& Watzl, B. (2012). Critical review: Vegetables and fruit in the prevention of chronic disease. European Journal of Nutrition, 51(6), 637-663.

https://doi.org/10.1007/s00394-012-0380-y 
Gucciardi, E., Vahabi, M., Norris, N., Del Monte, J. P., \& Farnum, C. (2014). The intersection between food insecurity and diabetes: A review. Current Nutrition Report, 3(4), 324-332. https://doi.org/10.1007/s13668-014-0104-4

Hung, H.-C., Joshipura, K. J., Jiang, R., Hu, F. B., Hunter, D., Smith-Warner, S. A., . . \& Willett, W. C. (2004). Fruit and vegetable intake and risk of major chronic disease. Journal of the National Cancer Institute, 96(21), 1577-1584. https://doi.org/10.1093/jnci/djh296

Volpe, S. L. (2019). A nutritionist's view: Fruit and vegetable intake and prevention of chronic disease. ACSM's Health and Fitness Journal, 23(3), 30-31. https://doi.org/10.1249/FIT.0000000000000474

Weinfield, N. S., Mills, G., Borger, C., Gearing, M., Macaluso, T., Montaquila, J., \& Zedlewski, S. (2014). Hunger in America 2014: National report. Chicago: Feeding America.

https://www.feedingamerica.org/sites/default/files/2020-02/hunger-in-america-2014-full-report.pdf 